\title{
Fabrication and Characteristics of Chitosan Non-woven Fabric developed using only water as plasticizer
}

\author{
Shin-Hee Lee ${ }^{\dagger 1)}$ and You-Lo Hsieh ${ }^{2)}$ \\ ${ }^{1)}$ Dept. of Clothing \& Textiles, Kyungpook National University; Daegu, Korea \\ ${ }^{2)}$ Division of Textiles and Clothing, University of California; Davis, USA
}

\begin{abstract}
This article describes a method for producing chitosan non-woven fabrics by just hot pressing without the use of a binder. A study has been made of the wet spinning of chitosan fiber. The fibers were rinsed thoroughly in running water and chopped wet into staples of with a length of approximately $5-10 \mathrm{~mm}$. The chopped chitosan staples were dispersed uniformly in water and fabricated using a non-woven making machine. This study examined the formation and the characteristics of chitosan non-woven fabrics manufactured by hot pressing without the use of a binder. The effects of the non-woven fabrication conditions on the thermal, morphological, structural, and physical properties of chitosan non-woven fabric with and without water as a plasticizer were studied. The temperature of the exothermic peak, decomposition of chitosan fibers increased with increasing heating rate. Water in the chitosan fiber effectively plasticized the chitosan fiber. The thermal bonded structure of the wet chitosan fiber with water as a plasticizer was clearly found in many parts of the non-woven fabric at a fabrication temperature of $200^{\circ} \mathrm{C}$. The intensity and profile of the $(100)$ plane $\left(2 \theta=10.2^{\circ}\right)$ and $(040)$ plane $\left(2 \theta=20.9^{\circ}\right)$ in the chitosan non-woven fabric decreases and became smooth in the non-woven fabric formation by melting.
\end{abstract}

Key words : chitosan, thermal bonding, non-woven fabric, plasticizer, water

\section{Introduction}

Chitosan is one of the most abundant natural polysaccharides and has been studied widely because of its non-toxic, biodegradable, biocompatible, bioactive, and antibacterial properties(Lee et al., 2010; Sergio et al., 2008). Chitosan has excellent fiber-forming ability and is wet spun, typically from $1-10 \mathrm{wt} \%$ chitosan acetic acid solutions into a basic coagulation bath. Chitosan fibers have been manufactured into woven and knitted textiles to be used as medicinal dressing materials, and as exclusive or additional fibrous components(Lee et al., 2004).

Non-wovens have been increasingly used for therapeutic applications for human that must be compatible with living tissues. Chitosan non-wovens are typically fabricated with binder materials such as PVA that are potentially problematic in these applications(Muzzarelli, 2009; Shalumona et al., 2009). It may be too much to say that such a binder material contained in the non woven fabric of chitosan fibers causes another trouble when the non woven fabric is used in a medical treatment in contact with the living tissues.

Strong intra- and intermolecular hydrogen bonds exist in chi-

$\dagger$ Corresponding author; Shin-Hee Lee

Tel. +82-53-950-6221, Fax. +82-53-950-6219

E-mail: shinhee@knu.ac.kr tosan and cellulose. The dissociation and reorganization of these hydrogen bonds by chemical modification gives rise to novel molecular conformations in the form of solutions, sols, hydrogels, fibers, films, and sponges(Grant et al., 1989; Jacek et al., 1990; Lee, 2003; Tokura et al., 1990).

This study developed a pure non-woven fabric using chitosan fibers as the matrix and water as the plasticizer. Water as a plasticizer will evaporate during compression molding, and the resulting non-woven fabrics are expected to have superior properties to those developed using glycerol or other plasticizers(Reddy \& Yang, 2011). Crofton and Pethrick(1982) suggested a conduction mechanism that involved hydroxyl group rotation followed by dissociation and subsequent proton migration leading, in turn, to resolved water relaxation in the region of ambient temperatures. Generally, there is a shift in the polymer sub-Tg relaxation processes to lower temperatures upon hydration, which suggests that mobile bound water acts as a plasticizer in this instance(Keely et al., 1995).

This study examined the formation and characteristics of chitosan non-wovens fabricated by thermal compression without the use a binder. The effects of the non-woven fabrication condition on the tensile properties and morphological properties of chitosan nonwoven fabric with and without water as a plasticizer were studied. 


\section{Experimental}

\subsection{Materials}

Chitin was derived from red crabs from the East Sea of Korea(Dongbo Chemical Company, Korea). Acetic acid(Aldrich) and sodium hydroxide(Fluka) were of reagent grade. Chitosan was deacetylated from chitin by heating $10 \mathrm{wt} \%$ chitin in a $50 \mathrm{wt} \%$ $\mathrm{NaOH}$ solution at $110^{\circ} \mathrm{C}$ for $3 \mathrm{~h}$. The solids were filtered and washed thoroughly with distilled water until the $\mathrm{pH}$ was neutral. The degree of deacetylation(\%) and viscosity-average molecular weight(Mv) of chitosan were $85.1 \%$ and 148,000 Daltons, respectively(Lee, 2003).

\subsection{Chitosan fiber spinning and non-woven formation}

Chitosan fibers were wet spun and wet laid into non-wovens, as depicted in the schematic process(Fig. 1). The chitosan spin dope was prepared by dissolving $4 \%(\mathrm{w} / \mathrm{v})$ chitosan in $2 \%(\mathrm{w} / \mathrm{w})$ aqueous acetic acid and homogenized by mechanical stirring for $12 \mathrm{~h}$, degassed, filtered and left standing at $20^{\circ} \mathrm{C}$ for $5 \mathrm{~h}$. The chitosan dope was extruded through a 1,500-hole Au-Pt alloy spinneret using a variable speed infusion-metering pump(BPB-4391, Zenith) into a $10 \%(\mathrm{w} / \mathrm{w})$ aqueous $\mathrm{NaOH}$ coagulation bath. The spinneret consisted of 1,500 holes at $0.1 \mathrm{~mm}$ diameter and a capillary length-todiameter ratio of 2. A 400-mesh(pore size, $37 \mu \mathrm{m}$ ) stainless steel filter was mounted behind the spinneret. The coagulated filaments were washed with water, drawn in a $99 \pm 1$ water bath to $130 \%$ and taken-up at a speed of $3.0 \mathrm{~m} / \mathrm{min}$.

The filaments were rinsed thoroughly in water and either dried or remain in the wet state. Either the dried or wet filaments were chopped to 5-10 $\mathrm{mm}$ long staples and dispersed uniformly in water

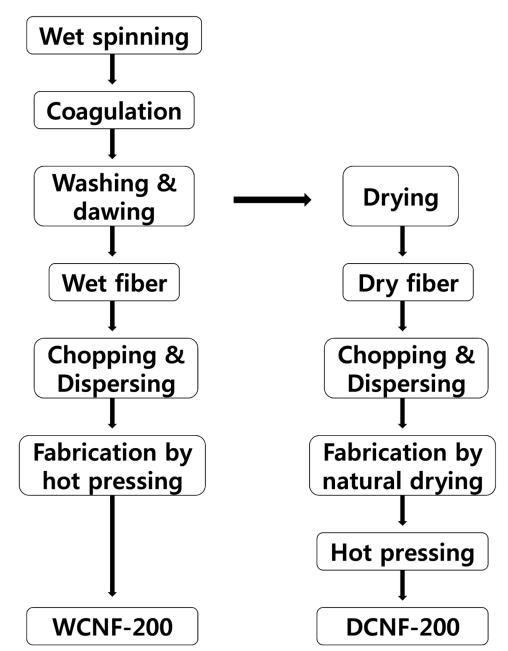

Fig. 1. Fiber spinning and nonwoven fabrication processes.

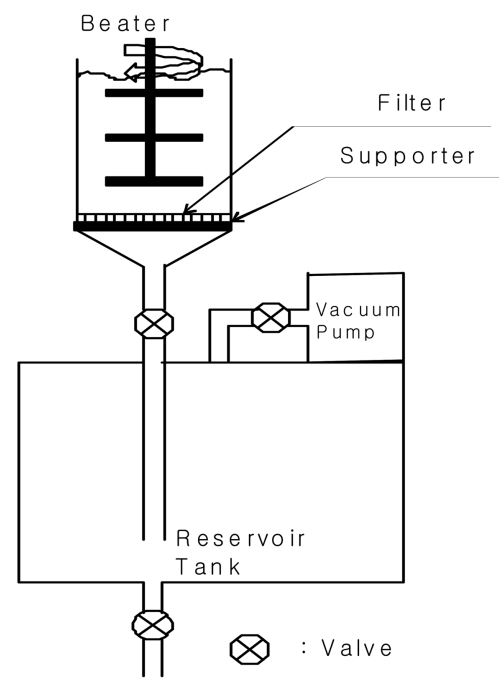

Fig. 2. Schematic diagram of the wet-laid nonwoven fabrication set-up.

and fabricated into non-wovens by $400-\mathrm{mesh}$ (pore size, $37 \mu \mathrm{m}$ ) stainless steel filter(Fig. 2). After removing the excess water by a vacuum pump, the wet chitosan fiber sheet was transferred to a $100 \mathrm{~mm}$ diameter hot 400 -mesh(pore size, $37 \mu \mathrm{m}$ ) stainless steel filter press whose lower plate heated by a $0.5 \mathrm{kw}$ heating apparatus and pressed under $3 \mathrm{kgf} / \mathrm{cm}^{2}$ at 160,180 or $200\left( \pm 5^{\circ} \mathrm{C}\right)$ for $20 \mathrm{sec}$ to be 400 -mesh(pore size, $37 \mu \mathrm{m}$ ) stainless steel filter designed as WCNF-160, WCNF-180 and WCNF-200, respectively. The control sample, DCNF-200, was fabricated from dry chitosan fibers and hot pressed under the same conditions as WCNF-200.

\subsection{Characterization}

The tensile properties of single filaments were measured at a $20 \mathrm{~mm}$ gauge length and a $20 \mathrm{~mm} / \mathrm{min}$ crosshead speed under standard conditions of $20^{\circ} \mathrm{C}$ and $65 \%$ relative humidity using a Tensilon instrument(model Vibrodyn A-4860, Lenzing Co.). The fineness of the fiber(denier) was measured, i.e. the mass in grams of a 9,000 m length, and used to normalize the fiber tenacity and modulus in gf/denier(Hirano \& Moriyama, 2004). The means and standard deviations of 20 tensile measurements were reported. The thermal behavior of the chitosan fibers and non-wovens were examined by differential scanning calorimetry (DSC model Q20, $\mathrm{TA}$ Instruments). The measurements were performed at 10 and $30^{\circ} \mathrm{C} /$ min heating rates from $30^{\circ} \mathrm{C}$ to $400^{\circ} \mathrm{C}$ in a nitrogen atmosphere. Thermogravimetric analysis(TGA-50, Shimadzu) was run in nitrogen at a $10^{\circ} \mathrm{C} / \mathrm{min}$ heating rate from $30^{\circ} \mathrm{C}$ to $800^{\circ} \mathrm{C}$. The imbibed water content of the chitosan fibers, in either dried or never dried state, was calculated as follows(Lee et al., 2004):

Imbibed water content $(\%)=\{(\mathrm{WF}-\mathrm{DF}) / \mathrm{DF}\} \times 100$ 
where WF and DF are the weights(g) of wetted and dried fibers, respectively. The wetted fiber weights were obtained by submerging the chopped fibers in water for $24 \mathrm{~h}$, followed by centrifugation(5,000 rpm for $5 \mathrm{~min}$ : $1736 \mathrm{MGR}$, Hanil SME Co. Ltd). The fibers were then dried at $105^{\circ} \mathrm{C}$ for $3 \mathrm{~h}$ to a constant weight to obtain the dried weight. The thickness of each non-woven was measured using a thickness gauge(Division of Atlas Electric Devices Co.). The morphology of the non-wovens was observed by a scanning electron microscope(FE-SEM, Hitachi S-430 \& EDX-350). The mechanical properties of the chitosan non-woven fabrics were determined using a universal testing machine(Instron 3365). The 10-mm wide and 50-mm long non-woven samples were tested using a $0.5 \mathrm{kgf}$ preload at a crosshead speed of $10 \mathrm{~mm} / \mathrm{min}$. The reported tensile stress, tensile strain and Young's modulus at maximum load were the means of five repetitions for each sample. Xray diffraction(XRD, Rigaku XG X-ray generator) of the chitosan non-wovens was performed at $35 \mathrm{kV}$ and $20 \mathrm{~mA}$. The scattered $\mathrm{X}$ rays in wide-angle XRD mode were monochromatized to $\mathrm{Cu} \mathrm{K} \alpha$ rays with a graphite monochromator and counted with a Rigaku Denki scintillation counter at $2^{\circ}$ intervals using a Rigaku D/Max2500 goniometer.

\section{Results and discussion}

\subsection{Chitosan Fibers}

The chitosan fibers obtained from wet spinning had a mean size, breaking tenacity, elongation, and work to rupture of 1.85 denier, $1.75 \mathrm{gf} / \mathrm{d}, 9.41 \%$ and $0.5 \mathrm{gf} / \mathrm{d}$, respectively, all with coefficients of variation of approximately $9 \%$ (Table 1 ). The imbibed water content of the dry and wet chitosan fiber were $43.4 \%$ and $75.3 \%$, respectively. Assuming water adsorbed similarly to the dried and never dried fibers, the $31.9 \%$ more imbibed water in the never dried chitosan fibers must be held internally, indicating substantial internal pores. This is consistent with previous reported microvoids in swollen fibers(Lee, 2000).

\subsection{DSC thermogram of dry and wet chitosan fiber}

Both dry and wet chitosan fibers were scanned at 10 and $30^{\circ} \mathrm{C} /$ min heating rates(Fig. 3). Fibers in either state showed similar

Table 1. Tensile properties of chitosan fibers

\begin{tabular}{lcc}
\hline & Mean value & Coefficient \\
\hline Fineness (denier) & 1.85 & 8.4 \\
Tenacity (gf/denier) & 1.75 & 9.7 \\
Elongation (\%) & 9.41 & 8.9 \\
Work to rupture $(\mathrm{gf} \cdot \mathrm{cm})$ & 0.50 & 9.2 \\
\hline
\end{tabular}
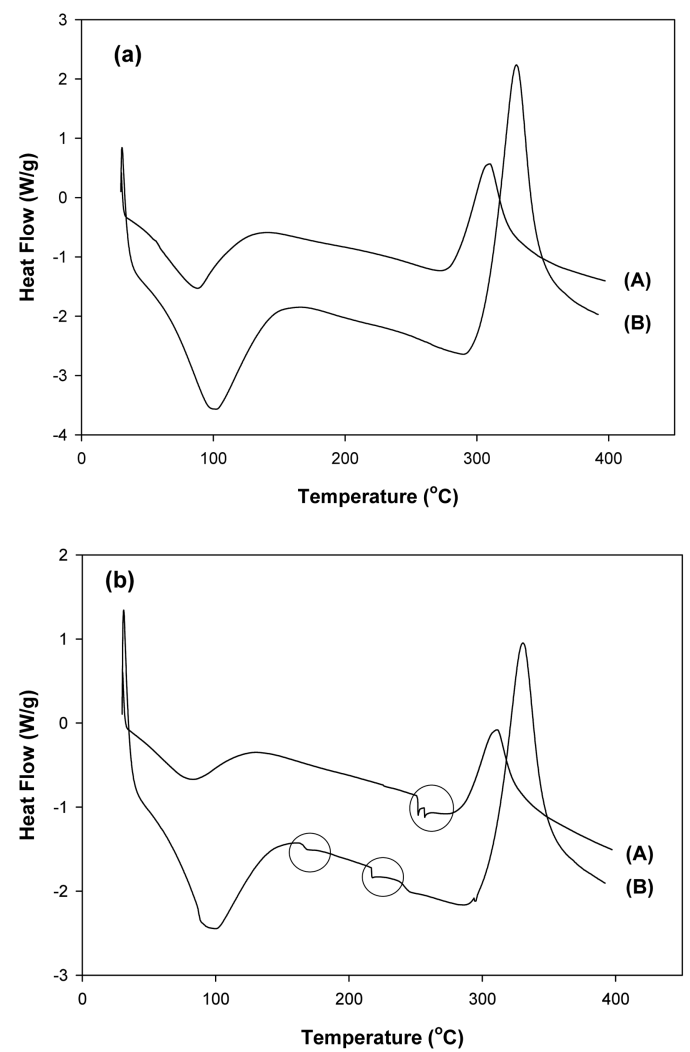

Fig. 3. DSC thermograms (in $\mathrm{N}_{2}$ ) of (a) dry and (b) wet chitosan fibers: (A) $10^{\circ} \mathrm{C} / \mathrm{min}$ and (B) $30^{\circ} \mathrm{C} / \mathrm{min}$.

broad moisture evaporation endotherms near $100^{\circ} \mathrm{C}$ and decomposition exotherms at around $310-330^{\circ} \mathrm{C}$, with both temperature selevated at the higher heating rates as expected. The main distinction was the small endothermic doublets on the wet fibers. The doublets were observed close together at 252 and $257^{\circ} \mathrm{C}$ at $10^{\circ} \mathrm{C} /$ min, but became more separated and lowered to 170 and $220^{\circ} \mathrm{C}$ when scanned at $30^{\circ} \mathrm{C} / \mathrm{min}$. The temperature of the endothermic peak decreased with increasing heating rate because the water in the chitosan fiber effectively plasticizes them. This shows that the water of wet chitosan fibers decreases the melting point of chitosan fibers because the water acts as a plasticizer(Shalumona et al., 2009). Higher temperatures for non-woven fabrication are necessary to ensure the complete removal of water used as a plasticizer from the chitosan fibers. The lower melting temperature of the chitosan fibers with water as a plasticizer allows the use of chitosan fibers as a matrix without damaging the chitosan. Water was reported to be effective as a plasticizer for polyacrylonitrile (Atureliya \& Bashir, 1993; Grove et al., 1998).

\subsection{Characteristics of the chitosan non-wovens}

The thickness(mm) of the chitosan non-wovens of WCNF-200 


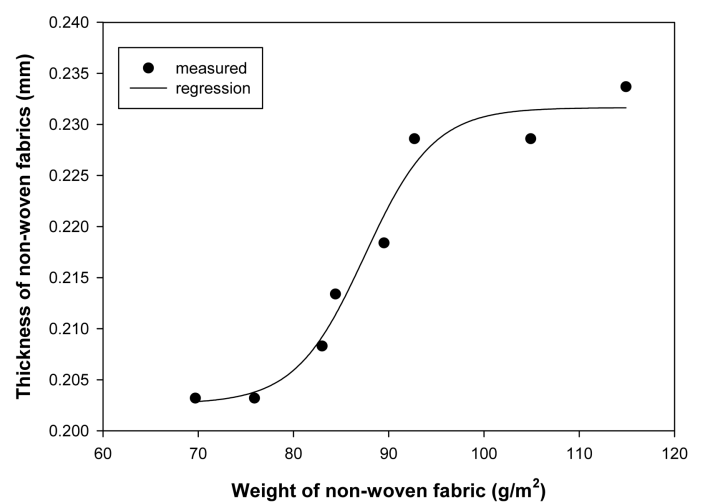

Fig. 4. Thickness and weight relationship of the chitosan non-wovens.

as a function of their weights ( $\mathrm{g}$ ) show the thickness increased linearly from around 0.205 to $0.230 \mathrm{~mm}$ in the 70 to $120 \mathrm{~g} / \mathrm{m}^{2}$ range(Fig. 4). Above this range, little gains in thickness with increasing weights suggests denser fiber packing. This result suggest that the thickness of non-woven fabric is controlled easily by varying fiber weights in the 70 to $120 \mathrm{~g} / \mathrm{m}^{2}$ range.

\subsection{SEM images of the chitosan non-woven fabric}

The morphology of hot pressed chitosan non-wovens was observed by SEM. Hot pressing of the wet chitosan fibrous nonwoven at $160^{\circ} \mathrm{C}$ for $20 \mathrm{~s}(\mathrm{WCNF}-160)$ showed deformation of few fibers on the surface(Fig. 5a). Such deformation of surface fibers became more obvious as the pressing temperature reached $180^{\circ} \mathrm{C}$ (Fig. 5b). Flattening of fibers, not only those on the surface, but also several layers below was observed on that hot pressed $200^{\circ} \mathrm{C}$ (Fig. 5 c). Completely merged fibers clearly indicate extensively bonded structure among the top few layers of fibers. The chitosan non-woven hot-pressed from dried fiber sheet exhibited no

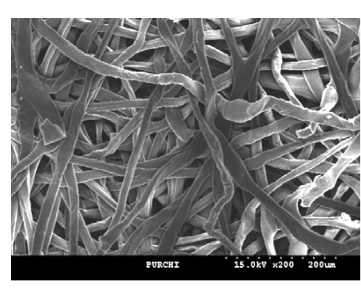

(a)

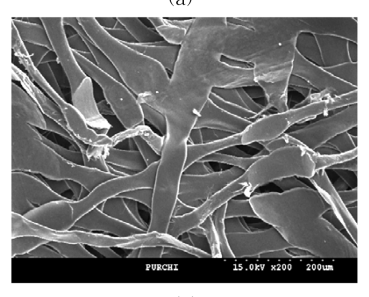

(c)

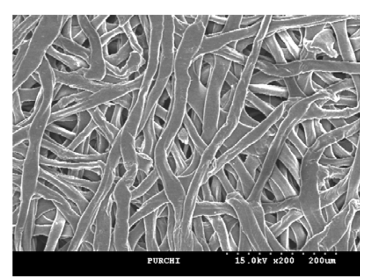

(b)

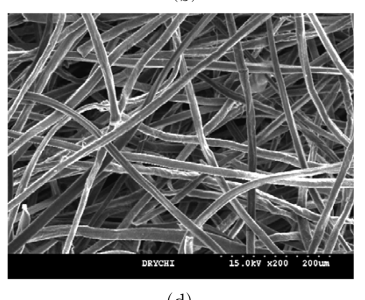

(d)
Fig. 5. SEM image of the surface of chitosan non-woven fabric - (a) WCNF-160, (b) WCNF-180, (c) WCNF-200, and (d) DCNF-200.

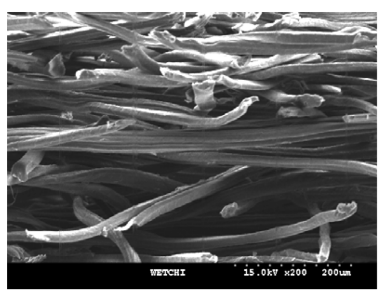

(a)

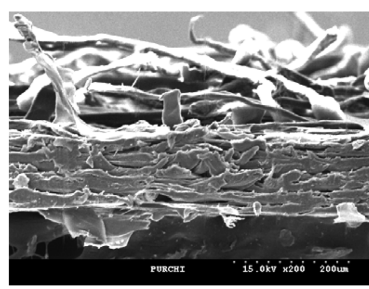

(c)

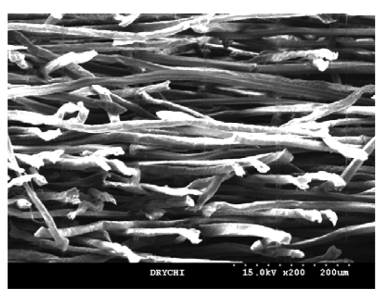

(b)

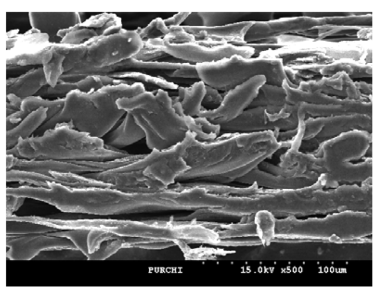

(d)
Fig. 6. SEM image of a cross-section of chitosan non-woven fabric - (a) Wet chitosan fiber and non hot press, (b) DCNF-200, (c) WCNF$200(\times 200)$, and (d) WCNF-200 $(\times 500)$.

deformation nor bonding among fibers(Fig. 5d). This is further supported by the observation of cross-sections of chitosan nonwovens. Hot pressed nonwoven from dried chitosan fibers at $200^{\circ} \mathrm{C}$ showed clearly separated individual fibers among the layers(Fig. 6a, b). In contrast, the nonwoven from hot pressing wet chitosan fibers at the same temperature showed much deformed and bonded structure(Fig. 6c, d). In fact, the hot pressed nonwoven from the wet state deformed considerably more than that from the dry state from the same shearing in sample preparation. Clearly, the thermally bonded structure of the nonwoven hot pressed from wet chitosan fibers showed the effect of water as a plasticizer. This is evidence that water effectively plasticizes the chitosan fibers and decreases the melting temperature to somewhat below $200^{\circ} \mathrm{C}$. This suggests that the wet chitosan fiber was easily fabricated by thermal bonding because the water effectively plasticizes the chitosan fiber and decreases the softening temperature. In addition, water was reported to be effective as a plasticizer for soy protein and wheat gluten (Pouplin et al., 1999; Reddy \& Yang, 2011).

\subsection{Thermal properties of chitosan non-wovens}

The DSC and TGA thermograms of chitosan non-woven fabric hot pressed at $200^{\circ} \mathrm{C}$ from dry and wet states showed them to exhibit similar thermal behavior(Fig. 7). Both DSC showed moisture endothermic peaks at approximately $100^{\circ} \mathrm{C}$ and associated 4$4.5 \%$ mass loss in the TGA thermograms. Similarly substantial exothermal peak occurred over the temperature range of $312-313^{\circ} \mathrm{C}$ and corresponded to $32-33 \%$ mass loss. Evidence of thermal decomposition of the crystalline structure was obtained in the temperature inter- 


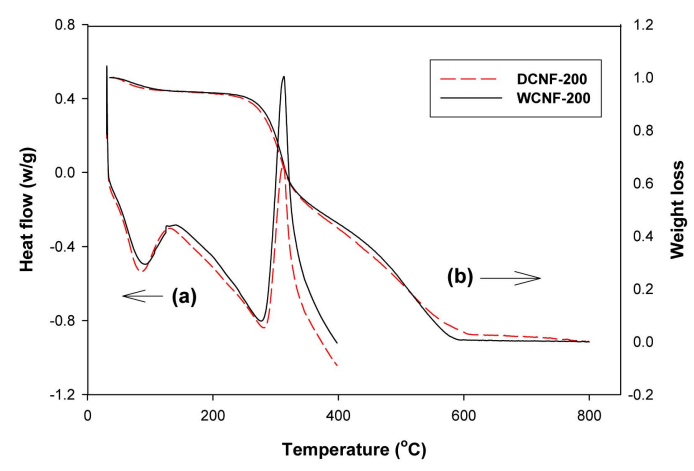

Fig. 7. DSC and TGA thermograms of the chitosan non-woven fabrics (heating rate : $10^{\circ} \mathrm{C} / \mathrm{min}$ ).

val of $310-350^{\circ} \mathrm{C}$, and an exothermal reaction within the polymer was observed in the case of chitosan non-woven fabrics. The maximum decomposition temperature of WCNF-200 and DCNF-200 was observed at approximately $312^{\circ} \mathrm{C}$, which was attributed to a complex process including the dehydration of saccharide rings, decomposition of the acetylated and deacethylated unit of the chitosan polymer(Alonso et al., 1983; Carlos et al., 1993).

\subsection{X-ray spectroscopy of the chitosan non-woven fabric}

Fig. 8 shows wide-angle XRD patterns of chitosan non-woven fabrics shown in Figure 5. Generally, the XRD patterns of chitosan fibers showed less-intense diffraction at the (020) plane near $2 \theta=$ $10.2^{\circ}$ and a moderately sharp intense diffraction at the (040) plane near $2 \theta=20.2^{\circ}$ (Lee et al., 2004). The sharp intense diffraction corresponds to a lateral repeat distance, or Bragg spacing, and is represented as the (040) orthorhombic or monoclinic diffraction. The intensity and profile of the (100) plane $\left(2 \theta=10.2^{\circ}\right)$ and $(040)$ plane $\left(2 \theta=20.9^{\circ}\right)$ in the chitosan non-woven fabric decreases and became smooth in the non-woven fabric formation by melting.

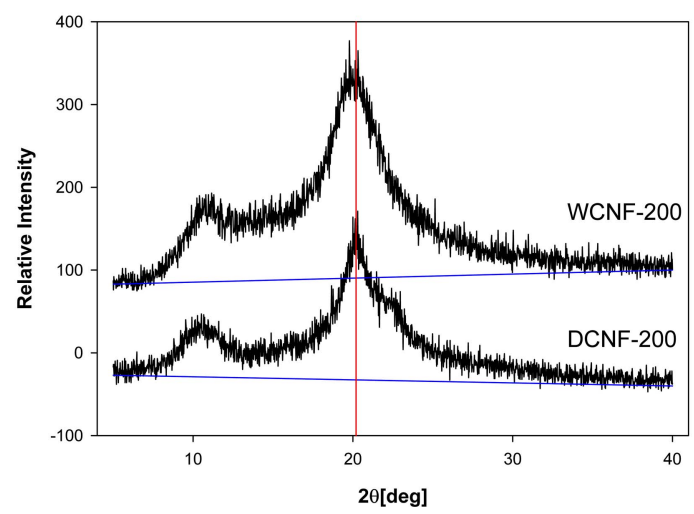

Fig. 8. XRD patterns of chitosan non-woven fabrics.
This suggests that with the thermal bonding of wet chitosan fiber, the d-spacing structure increased and chitosan molecules preferred to develop a looser crystalline form(Gao et al., 2007).

The degree of the crystallinity of chitosan non-woven fabrics was measured using the method proposed by Hermans and Weidinger(Hermans \& Weidinger, 1961). The degree of crystallinity of the chitosan non-woven fabrics were 0.39 and 0.36 for DCNF-200 and WCNF-200, respectively. This means that the crystallinity of the melted chitosan non-woven fabric, which was prepared from wet fiber, was lower than the crystallinity of nonmelted chitosan non-woven fabric, which was prepared from dry fibers because the crystal region of the non-woven fabric was decreased by melting. These results agree with Hasegawa et al who reported that the crystallinity of cellulose II in cellulose and cellulose-chitosan films decrease slightly with thermal treatment, even though the intensity of the $(100)$ plane $\left(2 \theta=10.2^{\circ}\right)$ in the chitosan film increased (Hasegawa et al., 1992).

\subsection{Tensile properties of the chitosan non-woven fabrics}

Table 2 lists the test results of stress and elongation at break of the non-woven fabrics of various thicknesses, which is controlled by the weight of used chitosan fiber for fabrication. Generally, with increasing thickness of the film, fabric, non-woven fabric, etc., non-woven fabrics are hard with high stiffness, strength, as well as low elongation. Increasing the thickness of non-woven fabric from $0.2032 \mathrm{~mm}$ to $0.2083 \mathrm{~mm}$ increased the tensile stress and Young's modulus by approximately $47 \%$ and $35 \%$, respectively. Further increasing the thickness of non-woven fabric from $0.2032 \mathrm{~mm}$ to $0.2337 \mathrm{~mm}$ increased the tensile stress and Young's modulus by approximately $148 \%$ and $145 \%$, respectively. Increasing the thickness of non-woven fabric increased the tensile stress and Young's modulus at break of the non-woven fabrics. On the other hand, the elongations at break of the non-woven fabrics were nearly the same in this experiment. On the other hand, WCNF-200 with a weight $114.9\left(\mathrm{~g} / \mathrm{m}^{2}\right)$ showed more than 80 and 43 times higher tensile strength and tensile modulus, respectively, than DCNF-200 with a

Table 2. Mechanical properties of the chitosan non-woven fabrics

\begin{tabular}{ccccc}
\hline \multicolumn{4}{c}{ Chitosan non-woven fabrics Tensile stress Tensile strain } & $\begin{array}{c}\text { Young's } \\
\text { Condition }\end{array}$ \\
$\begin{array}{c}\text { Thickness }(\mathrm{mm}) / \\
\text { Weight }\left(\mathrm{g} / \mathrm{m}^{2}\right)\end{array}$ & $\begin{array}{c}\text { Max Load at } \\
\left(\mathrm{kgf} / \mathrm{cm}^{2}\right)\end{array}$ & $\begin{array}{c}\text { Max Load } \\
(\%)\end{array}$ & $\begin{array}{c}\text { Modulus } \\
\left(\mathrm{kgf} / \mathrm{cm}^{2}\right)\end{array}$ \\
\hline $\begin{array}{c}0.2032 / 69.7 \\
\text { WCNF- }\end{array}$ & 0.2083 .32 & 0.75 & 5,097 \\
200 & $0.2184 / 83.0$ & 48.60 & 0.82 & 6,867 \\
& $0.2337 / 114.9$ & 61.74 & 0.74 & 9,953 \\
$\begin{array}{c}\text { DCNF- } \\
200\end{array}$ & $0.4100 / 118.5$ & 1.03 & 0.85 & 12,493 \\
\hline
\end{tabular}


weight $118.5\left(\mathrm{~g} / \mathrm{m}^{2}\right)$.

\section{Conclusions}

Water without any chemicals can effectively plasticize and produce chitosan thermoplastics. Wet chitosan fibers, a protofiber, which were prepared by wet spinning, were fabricated by just melting without the use of a binder. The imbibed water content of the dry and wet chitosan fiber were $43.4 \%$ and $75.3 \%$, respectively. The excess water of the wet chitosan fibers must be held internally and is most likely due to the many microvoids of the swollen fibers. Water of wet chitosan fiber decreases the melting temperature and can prepare pure chitosan non-woven fabric by just heating. Thermal bonding of the chitosan fiber sheet was not observed in the dry chitosan fibers without water as a plasticizer at a fabrication temperature of $200^{\circ} \mathrm{C}$. On the other hand, the thermal bonding structure of the wet chitosan fiber with water as a plasticizer was clearly found in many parts of the non-woven fabric. The tensile strength and modulus at break of the non-woven fabrics increased remarkably with increasing thickness of the non-woven fabric. WCNF200 with a weight of $114.9\left(\mathrm{~g} / \mathrm{m}^{2}\right)$ has more than 80 and 43times higher tensiles trength and tensile modulus, respectively, than DCNF-200 with a weight $118.5\left(\mathrm{~g} / \mathrm{m}^{2}\right)$. On the other hand, chitosan nonwoven fabric, which was prepared by hot-pressing, showed a slight change in micro-structure. The crystallinity, intensity of the (100) plane $\left(2 \theta=10.2^{\circ}\right)$ and $(040)$ plane $\left(2 \theta=20.9^{\circ}\right)$ of the chitosan non-woven fabric that used the wet fiber decreased slightly. Utilizing water as a plasticizer can not only allow the fabrication of chitosan non-woven fabric but also decrease the crystallinity of the non woven fabric.

\section{Acknowledgments}

This research was supported by Kyungpook National University Fund, 2011.

\section{References}

Alonso, J. G., Covas, C. P., \& Nieto, J. M. (1983). Determination of the degree of acetylation of chitin and chitosan by thermal analysis. Journal of Thermal Analysis and Calorimetry, 28(1), 189-193.

Atureliya, S. K., \& Bashir, Z. (1993). Continuous plasticized melt-extrusion of polyacrylonitrile homopolymer. Polymer, 34(24), 5116-5122.

Carlos, P. C., Waldo, A. M., \& Julio, S. R. (1993). A kinetic study of the thermal degradation of chitosan and a mercaptan derivative of chitosan. Polymer Degradation and Stability, 39(1), 21-28.

Crofton, D. J., \& Pethrick, R. A. (1982). Dielectric studies of cellulose and its derivatives: 2. Effects of pressure and temperature on relaxation behavior. Polymer, 23(11), 1609-1614.

Gao, Q., Wan, A., \& Zhang, Y. (2007). Effect of reacetylation and degradation on the chemical and crystal structures of chitosan. Journal of Applied Polymer Science, 104(4), 2720-2728. doi: 10.1002/app.25711

Grant, S., Blair, H. S., \& Mckay, G. (1989). Structural studies on chitosan other chitin derivatives. Macromolecular Chemistry and Physics, 190(9), 2279-2286.

Grove, D., Desai, P., \& Abhiraman, A. S. (1988). Exploratory experiments in the conversion of plasticized melt spun PAN-based precursors to carbon fibers. Carbon, 26(3), 403-411.

Hasegawa, M., Isogai, A., Onabe, F., Usuda, M., \& Atalla, R. H. (1992). Characterization of cellulose-chitosan blend film. Journal of Applied Polymer Science, 45(11), 1873-1879.

Hermans, P. H., \& Weidinger, A. (1961). Quantitative investigation of the X-Ray diffraction picture of some typical rayon specimens, Part I. Textile Research Journal, 31(6), 558-571.

Hirano, S., \& Moriyama, T. (2004). Some novel N-(carboxyacyl) chitosan filament. Carbohydrate Polymers, 55(3), 245-248.

Jacek, D., Lidia, S., Magdalena, K., Luba, J., \& Ryszard, C. (1990). Structure-bioactivity relationship of chitin derivatives-Part I: The effect of solid chitin derivatives on blood coagulation. Journal of Bioactive and Compatible Polymer, 5(3), 293-299.

Keely, C. M., Zhang, X., \& McBrierty, V. J. (1995). Hydration and plasticization effects in cellulose acetate: a solid-state NMR study. Journal of Molecular Structure, 355(1), 33-46.

Lee, S. H. (2003). Ripening time and fiber formation of chitosan spinning dope. Journal of Applied Polymer Science, 90(10), 2870-2877.

Lee, S. H. (2000). The mechanism and characteristics of dry-jet-wet spinning of chitosan fibers. Journal of Korean Fiber Society, 37(7), 7-15.

Lee, S. H., Kim, M. J., \& Park, H. S. (2010). Characteristics of cotton fabrics treated with epichlorohydrin and chitosan. Journal of Applied Polymer Science, 117(2), 623-628. doi:10.1002/ app.31351

Lee, S. H., Park, S. Y., \& Choi, J. H. (2004). Fiber formation and physical properties of chitosan fiber crosslinked by epichlorohydrin in a wet spinning system: The effect of the concentration of the crosslinking agent epichlorohydrin. Journal of Applied Polymer Science, 92(3), 2054-2062.

Muzzarelli, R. A. A. (2009). Chitins and chitosans for the repair of wounded skin, nerve, cartilage and bone. Carbohydrate Polymers, 76(2), 167-182.

Pouplin, M., Redl, A., \& Gontard, N. (1999). Glass transition of wheat gluten plasticized with water, glycerol, or sorbitol. Journal of Agricultural and Food Chemistry, 47(2), 538-543.

Reddy, N., \& Yang, Y. (2011). Completely biodegradable soyprotainjute biocomposites developed using water without any chemicals as plasticizer. Industrial Crops and Products, 33(1), 35-41. doi: 10.1016/j.indcrop.2010.08.0

Sergio, T. G., Ocio, M. J., \& Lagaron, J. M. (2008). Development of active antimicrobial fiber used chitosan polysaccharide nanostructures using electrospinning. Engineering in Life Sciences, 8(3), 303-314. doi: 10.1002/elsc.200700066

Shalumona, K. T., Binulala, N. S, Sevamurugana, N., Naira, S. V., Menona, 
D., Furuikeb, T., Tamurab, H., \& Jayakumar, R. (2009). Electrospinning of carboxymethyl chitin/poly(vinyl alcohol) nanofibrous scaffolds for tissue engineering applications. Carbohydrate Polymers, 77(4), 863-869. doi:10.1016/j.carbpol 2009.03.009

Tokura, S., Baba, S., Uraki, Y., Miura, Y., Nishi, N., \& Hasekawa, O.
(1990). Carboxymethyl-chitin as a drug carrier of sustained release. Carbohydrate Polymers, 13(3), 273-281.

(Received 7 January 2014; 1st Revised 20 January 2014; 2nd Revised 27 January 2014; Accepted 10 March 2014)

Copyright (C) 2014 (by) the authors. This article is an open access article distributed under the terms and conditions of the Creative Commons Attribution license (http://creativecommons.org/licenses/by/3.0/), which permits unrestricted use, distribution, and reproduction in any medium, provided the original work is properly cited. 